Revista Posgrado y Sociedad

Sistema de Estudios de Posgrado

Universidad Estatal a Distancia

ISSN 2215-2172

Costa Rica

revistaposgradoysoci@uned.ac.cr

\title{
El potencial Riesgo de Gobierno Corporativo en la \\ Banca Estatal Costarricense derivado de sus Juntas Directivas
}

The potential Corporate Governance Risk in the Costa Rican State Banks derived from their Boards of Directors

\author{
Alejandra Gutiérrez Segnini \\ Universidad Estatal a Distancia
}

Volumen 13, Número 1

Marzo 2013

p. 1-15

Recibido: Octubre, 2011

Aprobado: Marzo, 2012 


\begin{abstract}
Resumen
En todas las crisis bancarias que han existido, la gestión ha jugado un papel importante como iniciador potencial o como un multiplicador de las pérdidas y las distorsiones económicas, adquiriendo relevancia así el riesgo de gobierno corporativo en las entidades financieras.

La junta directiva es el elemento central y fundamental para un buen gobierno corporativo, por lo que su debida conformación y desempeño es clave para la entidad.

Muchos de los estándares de buenas prácticas en la materia ya están contenidos en varios cuerpos normativos del ordenamiento jurídico costarricense, no obstante, hay ciertas debilidades y vacíos que generan malas prácticas en cuanto a la composición y funcionamiento de las juntas directivas de la banca estatal, lo cual aumenta el riesgo de gobierno corporativo en estas entidades.

Así pues, se presentan una serie de recomendaciones que podrían subsanar las debilidades halladas, pero en general lo que se pretende es hacer consciencia de las implicaciones del tema, para así modificar la visión que se maneja en Costa Rica en cuanto a éstos órganos colegiados, de forma tal que las personas que lideren y fijen el norte de las entidades financieras estatales tengan el perfil necesario para llevar a cabo sus tareas eficazmente.

Palabras clave: Banca, gobierno corporativo, riesgo, junta directiva.
\end{abstract}

\begin{abstract}
In all banking crisis that have existed, management has played an important role as potential initiator or increasing the losses and economic distortions, therefore drawing attention towards the corporate governance risk in financial entities.

The Board is fundamental to good corporate governance so that its proper composition and performance.

Many international good practices in this matter are contained in the Costa Rican legal framework. However, certain weaknesses and gaps found may be generating bad practices in terms of composition and performance of the boards of directors in state banks, which increases the corporate governance risk in these institutions.

Thus, we present a series of recommendations that could correct the weaknesses found, but basically this proposal is intended to raise awareness of the implications of this matter, and so modify the vision in Costa Rica of the bank boards, so that the people that lead and set the course of these financial institutions have the profile required to carry out their tasks effectively.
\end{abstract}

Keywords: bank, corporate governance, risk, boards 


\section{Introducción}

El gobierno corporativo de una empresa es el conjunto de normas y conductas por el cual la misma es dirigida y controlada; incluye la manera en que se rigen las relaciones entre los accionistas, la junta directiva y la gerencia de la empresa, es decir, gestiona las relaciones entre los tres niveles: propiedad, administración y gestión; así como también establece las reglas del juego, creando un sistema de contrapesos dentro de la organización.

Un buen gobierno corporativo implica que la empresa esté mejor ordenada, planifique mejor sus objetivos $\mathrm{y}$ estrategias y responda de forma más eficiente en sus procesos. Bancos con una sólida estructura de gobierno corporativo son menos volátiles; sí sufren por el mercado -como todos-, pero no tanto.

Ahora bien, al pertenecer a la industria con mayor riesgo sistémico, la importancia de un buen gobierno corporativo aumenta en las entidades bancarias, dado que si éste es débil, contribuye al mal desempeño bancario, a que se generen pérdidas en la entidad, y con ello a una posible quiebra, acarreando a su vez graves consecuencias macro económicas.

Con lo anterior se describe el denominado riesgo de gobierno corporativo, riesgo que por un mal funcionamiento del gobierno interno de una entidad se afecte el desempeño de la empresa, con el agravante de que éste influye en la administración general de los demás riesgos, máxime si tomamos en cuenta la responsabilidad que tiene la junta directiva en la definición de políticas de riesgo de la entidad.

Prueba de esto es que en todas las crisis bancarias que han existido, la gestión ha jugado un papel importante como iniciador potencial o como un multiplicador de las pérdidas y las distorsiones económicas. La crisis que estalló en Estados Unidos a finales del 2008 no fue excepción, en tanto evidenció serias deficiencias en las juntas directivas de los grandes bancos, donde la gestión de riesgos y los sistemas de incentivos distorsionados apuntaron a una supervisión deficiente de dicho órgano, suscitando dudas sobre su capacidad para fiscalizar adecuadamente la labor de la gerencia y de comprender y controlar el negocio en sí mismo.

Así pues, la junta directiva es el elemento central y fundamental para un buen gobierno corporativo. En ella deben concentrarse todos los esfuerzos de transparencia, ecuanimidad, eficiencia y profesionalismo, para ejemplo de todos los funcionarios de la sociedad.

Por ser el "corazón del Gobierno Corporativo", la junta directiva ejerce labores de direccionamiento estratégico, ejecución, control y seguimiento al desempeño de la organización en el logro de sus objetivos, lo cual implica que si la mayoría de directivos de un banco no tiene la formación, experiencia $o$ perfil para entender y debatir la 
opinión de la gerencia sobre el futuro de la empresa, su apetito por el riesgo y los diferentes tipos de negocios cada día más complejos que realiza un banco, no se puede esperar que la gestión por parte de este órgano sea buena.

Por todo lo anterior, es pertinente analizar a las juntas directivas de la banca estatal de Costa Rica, donde el Banco Nacional, el Banco de Costa Rica, y Bancrédito, aparte de ser los entes financieros líderes en el mercado -que dentro de nuestro contexto vendrían a ser too big to fail-, cuentan con garantía del Estado. Dicha garantía implica que en caso de que estos bancos no puedan hacerle frente a sus obligaciones, su ejecución significaría trasladar al contribuyente el riesgo de la actividad bancaria, pero además, que dicha garantía genera muchas veces una significativa tranquilidad a los directivos públicos a los que se confían las empresas del Estado, quienes al no tener la figura de accionista propiamente dicha, no tienen quien directamente les exija cuentas de su gestión y les demanden ciertos resultados, lo que evidentemente aumenta el riesgo moral.

Como bien lo señalan las Directrices de la OCDE sobre el Gobierno Corporativo de las Empresas Públicas publicadas en el 2011, "las empresas públicas pueden sufrir tanto por un intervencionismo indebido y por unas interferencias de la propiedad por motivaciones políticas, como por una propiedad totalmente pasiva 0 distante por parte del Estado. También se puede producir una dilución de la responsabilidad ya que los resultados de las empresas públicas conlleva una compleja cadena de agentes (la administración, el Directorio, entidades propietarias, ministerios, el gobierno), sin claros y fácilmente identificables, o remotos, principales a los que rendir cuentas. “ En fin, un buen gobierno corporativo necesita bases jurídicas, reguladoras e institucionales que sean adecuadas y eficaces. El gobierno corporativo de las entidades bancarias costarricenses viene definido por la Ley Orgánica del Sistema Bancario Nacional de 1953, lo que implica que sus disposiciones no necesariamente se ajustan a los requerimientos actuales para una institución bancaria sólida y competitiva, y desde aquí se empiezan a afectar el desempeño de funciones y se puede generar el síndrome diplodocus: mucho cuerpo y poca cabeza.

\section{Desarrollo}

El análisis consistió en la revisión de las normas que regulan a dichas juntas directivas frente a los estándares internacionales de gobierno corporativo, haciendo especial énfasis en la conformación de éstos órganos.

En cuanto al funcionamiento de una junta directiva, el sexto Principio de la OCDE establece que "El marco para el gobierno corporativo deberá garantizar la orientación estratégica de la empresa, el control efectivo de la dirección ejecutiva por parte del Consejo y la responsabilidad de éste frente a la empresa y los accionistas." A partir de dicho principio, se establecen varios estándares sobre buenas prácticas de gobierno, dentro 
de los cuales destacamos el hecho de que los directores tienen responsabilidad con respecto al sano manejo del banco, lo cual implica un deber de vigilancia.

En la práctica bancaria, dicho deber de vigilancia se ha dividido en dos deberes principales: la lealtad obligación de cuidar el negocio ajeno como si fuera el propio anteponiendo los intereses de la entidad a los propios en caso de conflictos de intereses-, y la diligencia -sujeción a un estándar de buen hombre de negocios que los directores deben satisfacer, y que, solo contando con conocimiento mínimo del negocio se puede valorar-.

Señalan también dichos principios que el Consejo deberá desempeñar determinadas funciones clave, dentro de las cuales se destacan las siguientes:

1. Función estratégica: implica la revisión y orientación de la estrategia de la empresa, de los principales planes de actuación, de los presupuestos anuales; implica también que la junta directiva debe establecer los objetivos y llevar un control del plan previsto y de los resultados obtenidos por la empresa, así como definir la política de riesgos de la institución, la cual abarcará la especificación de los tipos y grados de riesgo que una empresa está dispuesta a aceptar en su intento por cumplir sus objetivos.

2. Garantizar la integridad de los sistemas de presentación de informes contables y financieros, la disponibilidad de sistemas de control adecuados (principalmente sistemas de gestión de riesgos y de control financiero y operativo), y garantizar la adecuación de estos sistemas a la ley y normativas aplicables: Esto implica que aún ahora cuando cada vez más responsabilidad recae en los comités de auditoria, esta obligación todavía recae en la junta directiva en su conjunto, sin que los exima cualquiera que sea el asesoramiento que reciben. En general, se determinó que muchos de los estándares de buenas prácticas están contenidos en varios cuerpos normativos del ordenamiento jurídico costarricense, como son la Ley Orgánica del Sistema Bancario Nacional (LOSBN), la Ley General de Control Interno, la Ley contra Corrupción y el Enriquecimiento Ilícito en la Función Pública, la Ley General de Administración Pública; en el Reglamento de Gobierno Corporativo, el Reglamento sobre Administración Integral de Riesgos y Reglamento para la Autorización y Ejecución de Operaciones con Derivados Cambiarios emitidos por el Conassif, $\mathrm{y}$ en las Directrices Generales sobre Principios y Enunciados Éticos emitidas por la Contraloría General de la República (CGR).

En cuanto al papel de la junta directiva en la entidad, sus funciones y responsabilidades, la normativa en Costa Rica en principio es reflejo de una concepción avanzada de ésta, que no sólo la percibe en su concepción tradicional -como un órgano de 
control- sino como órgano de asesoramiento y formulación de estrategias, dejando su ejecución práctica a la línea de gerencia a la cual controla, y rindiendo cuentas a los accionistas (que en caso de la banca estatal no existen pero lo ejerce por representación el Consejo de Gobierno).

No obstante, hay ciertas debilidades y vacíos en nuestro marco jurídico que generan que en la práctica prive la concepción tradicional y pasiva de las juntas directivas.

Lo anterior puede estar generando malas prácticas en cuanto a la conformación y funcionamiento de estas juntas directivas $\mathrm{y}$, dado que los bancos estatales tienen conglomerados financieros cuya asamblea de accionistas la integran a su vez los miembros de junta del banco, las debilidades se replican en sus empresas (sociedades administradoras de fondos de inversión, puestos de bolsa, comercializadoras de seguros, operadoras de pensiones), lo cual aumenta el impacto que malas decisiones puedan tener en la solidez de las entidades, por el consabido riesgo de que se produzca un efecto dominó a lo interno de todo el conglomerado y en la estabilidad del sistema financiero nacional.

\section{Debilidades \\ propuestas}

Conformación de las juntas directivas: Aquí se encuentran las principales debilidades, que a su vez inciden en el desempeño de las funciones atribuidas a la junta directiva, dado que la forma de escogencia y la integración de este órgano es un factor determinante en su accionar.

Para que la junta sea un órgano activo, que promueva la eficiencia y el debate estratégico real, debe tener una composición adecuada, tiempo suficiente, así como miembros competentes y participativos.

Es importante que exista un comité de nombramientos para especificar las calificaciones y la experiencia de los miembros de una junta y los requerimientos para identificar a las personas adecuadas de manera que el nombramiento se realice de conformidad con los requisitos, perfiles y competencias definidos por la organización, para asegurar el logro del objetivo del negocio, todo mediante un procedimiento de elección formal y transparente.

También quienes nombran y eligen directores deben asegurarse que los designados tengan a su disposición tiempo adecuado disponible para dedicarse a sus responsabilidades ya que, aunque puedan presentar las calificaciones profesionales apropiadas, pueden no ser apropiados debido a que sus otras obligaciones les impiden tener suficiente tiempo para ejercer sus tareas como directores.

En cuanto al número concreto de miembros, deberá ser el adecuado a las necesidades de la entidad, de forma que se maximice la eficiencia en su actuación y se alcance un funcionamiento más participativo, eficaz y eficiente. No deben ser mayores de lo estrictamente necesario para el ejercicio de la actividad porque, entre más grandes se hagan las juntas, más probable es que se 
convierta en práctica común que las decisiones importantes se decidan de antemano por un comité interno.

No obstante las buenas prácticas descritas, en Costa Rica el artículo 20 de la LOSBN que regula la elección y nombramiento de los miembros de junta directiva para la banca estatal presenta varios problemas:

-Tamaño predefinido: Cada junta directiva debe estar integrada por siete miembros, sin embargo, como vimos, debería tomarse en cuenta las necesidades propias de cada banco en particular

-Ausencia de proceso de elección: Dicho artículo señala únicamente que sus miembros serán nombrados por el Consejo de Gobierno a partir del $1^{\circ}$ de junio del año en que se inicia el período presidencial. No hay un proceso de elección de miembros, sólo se prevé que la persona nombrada cumpla con los requisitos mínimos (que como veremos son tan amplios que cabe el nombramiento de casi cualquier persona), pero no se sabe cómo se llega a ese nombramiento al no estar documentados los criterios que el Consejo de Gobierno utilizó, lo cual es un indicio de que es una escogencia "a dedo".

-Nombramientos interinos: $\mathrm{El}$ Consejo de Gobierno puede efectuar nombramientos interinos para sustituir a los directores que no puedan concurrir a sesiones justificadamente por períodos no menores de un mes ni mayores de un año. Esto códigos de buenas prácticas como el panameño y el brasileño establecen que no es recomendable, en virtud de que la eficacia del gobierno corporativo depende en gran medida de la continuidad que tengan las personas que lo ejercen, y un suplente no estará adecuadamente familiarizado con los asuntos de la compañía para poder tomar decisiones coherentes dentro del contexto de una gestión completa.

En virtud de lo anterior, y dado que no tienen accionistas, la recomendación es que sean los propios bancos estatales los que definan los perfiles de los miembros que vayan a conformar su junta directiva, de forma tal que puedan transmitir sus necesidades de conformidad con las características actuales del negocio.

Se recomienda que sea mediante concurso, a través de un procedimiento formal y transparente, con la definición de los requisitos para poder ser candidato. Además, es significativamente importante la aplicación de pruebas de idoneidad para verificar la competencia técnica y profesional de los potenciales miembros.

Luego, cada Banco deberá presentar a Superintendencia General de Entidades Financiera (SUGEF) la lista de elegibles para que sea éste órgano quien valore la idoneidad $y$ cumplimiento de requisitos, y así apruebe $o$ impruebe en primera instancia el nombramiento, debiendo revelar sus procedimientos y criterios de valoración. 
El nombramiento siempre debe quedar en manos del Consejo de Gobierno, de las listas de elegibles aprobadas por el regulador, en función de la propuesta de los bancos motivada en las condiciones personales, funcionales y técnicas de los candidatos.

Así pues, lo anterior se podría normar mediante Reglamento emitido por el Conassif, donde se especifique el procedimiento de elección de los miembros y se delimiten las potestades de cada parte (banco, supervisor, gobierno), con la respectiva reforma del artículo 20 de la LOSBN previendo esta posibilidad. Además, se recomienda eliminar la posibilidad de los nombramientos interinos.

Ahora bien, específicamente en cuanto a la idoneidad de los miembros, existen varios aspectos que se deben tomar en cuenta.

Como bien lo indica en su principio 1 el Comité de Basilea: "Los miembros del consejo deberán ser aptos para sus cargos, comprender claramente sus funciones en el gobierno corporativo y ser capaces de aplicar su buen juicio en asuntos que atañan al banco".

Para seleccionar los directores es importante tener en cuenta cualidades como experiencia laboral, comportamiento ético, formación académica, independencia, etc., con el fin de buscar la profesionalización en la gestión de la organización.

La experiencia relevante es un aspecto crucial de la efectividad de la junta. Los directivos deberían contar con antecedentes apropiados para ser capaces de comprender el negocio y las implicaciones financieras de las opciones estratégicas de la compañía, hacer preguntas relevantes $\mathrm{y}$ analíticas, así como tomar decisiones bien informadas. Lo anterior es particularmente importante en instituciones bancarias complejas, donde se requiere un número importante de directores con experiencia en la industria financiera. A pesar de lo anterior, en Costa Rica los requisitos del artículo 21 LOSBN para pertenecer a una junta directiva de la banca estatal son los criterios imperantes en el año 1988, a saber:

1. Ser costarricense.

2. Haber cumplido 25 años de edad. (Este mínimo de edad no es congruente con el siguiente inciso.)

3. Tener reconocida experiencia bancaria o amplios conocimientos en cuestiones económicas, o experiencia en problemas relativos a la producción nacional.

Al menos cuatro de los directores deberán poseer grado académico en el nivel de licenciatura, o título profesional equivalente. De ellos, al menos uno deberá ser licenciado en Ciencias Económicas y otro en Derecho.

Si bien es cierto, el requerimiento de tener reconocida experiencia bancaria es importante, el resto del artículo establece criterios tan amplios y simples que da margen a que se nombren personas totalmente ajenas al sector financiero.

En cuanto al requerimiento de que un miembro sea licenciado en Ciencias Económicas y otro en Derecho, perfectamente puede darse en la práctica el supuesto de que nunca hayan ejercido la profesión, pues la norma al respecto es poco concreta, e 
incluso aún habiendo practicado la profesión, ello no es garantía de que tengan conocimientos relacionados con la actividad bancaria.

No se toman en cuenta las necesidades de la propia entidad en cuanto a qué perfiles necesitan para mejorar el funcionamiento del banco, ni tampoco se prevé la participación del regulador.

Lo anterior se puede prestar para que se realicen nombramientos fundamentalmente con base en factores de política partidista, amistad o parentesco, sin importar si las personas tienen los requisitos necesarios -capacidad técnica, currículum, experiencia en el área, etc.- para desempeñar esas funciones. Pero dicha problemática no se ve en únicamente en la banca, sino que es un problema país. La Contraloría General de la República en su Informe sobre los Perfiles Gerenciales en algunos Ministerios e Instituciones del Sector Público publicado en el 2011, determinó que un $73 \%$ (80 de 110) de los jerarcas analizados, no cumplían a su vez, con requisitos de formación profesional y experiencia tanto en la actividad sustantiva de la entidad como en la gerencial, según las tendencias contemporáneos indispensables para atender las exigencias de la sociedad actual.

No escapa Costa Rica al fenómeno denominado "la Puerta Giratoria" ( The revolving door), que implica el conflicto de interés creado por el continuo movimiento de personas influyentes- entre los sectores privado y público, y entre el sector regulado y el sector regulador, permitiendo a representantes de cierta élite social o política, alternarse en cargos del gobierno y los puestos ejecutivos de sus empresas, creando así un círculo vicioso de poder.

Tenemos que hacer conciencia y aplicar medidas para evitar que personas sin el perfil idóneo sean jerarcas de instituciones del sector público. Señala dicho informe que "los cuadros gerenciales en la Administración Pública no pueden ser dejados en manos de personas que no ostenten cualidades o competencias que les permitan dirigir adecuadamente la serie de recursos humanos, técnicos y financieros que tienen a cargo, por cuanto son los principales responsables de articular y dirigir la serie de Políticas, Objetivos, Planes, Proyectos y acciones que buscan desarrollar el Poder Ejecutivo como tal."

A partir de lo anterior, y en el caso concreto de la banca estatal, sería importante que el perfil establecido para sus directores considere varios aspectos dentro de los cuales destacamos que haya miembros con formación académica en banca $\mathrm{y}$ finanzas, así como con experiencia en otras juntas directivas, en alta gerencia, que conozcan sobre gestión de riesgos, que tengan sólidos conocimientos del mercado nacional y el internacional.

También es importante que entre sus miembros haya profesionales con competencia técnica para interpretar 
informes y estados financieros $\mathrm{y}$ también con conocimientos en tecnología y, por tratarse de un banco estatal, el perfil podría incluir calificaciones relacionadas con las obligaciones y objetivos de política específicos de las empresas públicas. Incluso, las Directrices de la OCDE sobre el Gobierno Corporativo de las Empresas Públicas señalan que resulta aconsejable que algunos de sus miembros procedan del sector privado, lo cual contribuirá a que los Directorios estén más orientados a los negocios, especialmente en el caso de las empresas públicas que actúan en mercados competitivos -como es el caso de los bancos-

Asimismo, si el banco es la cabeza de un conglomerado financiero, esto también debe tomarse en cuenta, dado que los miembros también dirigirán empresas que se desenvuelven en el mercado bursátil, de seguros y de pensiones.

Normativamente, para lograr esto se tienen dos opciones: o reformar el artículo 21 de la LOSBN para dejar abierto el perfil de los miembros de junta y que éstos sean desarrollados por los bancos de conformidad con el reglamento que al efecto emita el Conassif; o bien, mantener el artículo -que de todas formas es muy amplioy que se concreten vía reglamento. Claro está que la idea es que los perfiles requeridos puedan ir variando con el tiempo conforme a las necesidades actuales de cada banco.

En cuanto al cargo de Presidente de la junta, sería también importante que se defina el perfil que debe tener éste miembro, el cual debería contar con más experiencia en banca $\mathrm{y}$ en empresas grandes y complejas. Además, en virtud de que sus funciones demandan una dedicación significativa, se podría valorar la posibilidad de tenerlo a tiempo completo. Respecto de este puesto se podría mantener el artículo 35 general de la LOSBN y que se concrete el perfil vía reglamento.

Cabe la mención que deberían existir más mujeres miembros de juntas directivas a partir de lo establecido en la Ley de Promoción de la Igualdad Social de la Mujer, pero no bajo un enfoque de cumplir con la cuota debida -como muchas veces se hace-, sino que las mujeres, al igual que los hombres, accedan a dicho cargo en virtud de su idoneidad, en iguales condiciones de acceso.

Otros aspecto importante de la calidad de la junta es la presencia de directivos externos que no tengan otra relación con la compañía más que la de sus puestos en la junta, para evitar que se integre con individuos que tengan lealtades con la gerencia y que sea poco probable que cuestionen las decisiones que la administración toma con respecto a la compañía.

Señala el artículo 23 LOSBN que el cargo de miembro de una junta directiva de la banca estatal es incompatible con los gerentes, personeros y empleados del propio banco. Lo anterior lo repite el Reglamento de Gobierno Corporativo en su artículo 5. Sin embargo, es una regla que realmente no aporta valor en tanto las buenas prácticas establecen que lo idóneo es que exista un balance entre miembros externos y miembros ejecutivos (los que trabajan 
en la alta administración de la entidad).

Lo anterior en virtud de que, si bien los directores externos pueden traer un nuevo punto de vista y desafío a los procesos de pensamiento existentes en una junta, necesitan tiempo para aprender suficientemente sobre el negocio como para hacer una contribución real, mientras que los directores internos o ejecutivos se caracterizan por tener un conocimiento pleno del negocio y motivación para que salgan bien las cosas ya que han sido parte de quienes llevan las decisiones a la práctica, además de que al existir un balance, más ejecutivos son directamente responsables.

Por esto se recomienda derogar el inciso 2 del artículo 23 y el artículo 31 de la LOSBN, y lo establecido en el Reglamento de Gobierno Corporativo. Eso sí, el Gerente no debe ser también presidente de la junta directiva, ya que esto conduce a una abrumadora concentración de poder y existe la tentación de abuso.

En cuanto a la retribución

Como principio general se sugiere que para el buen funcionamiento de una empresa, el Directorio debe estar suficientemente remunerado.

Una de las principales responsabilidades del Estado con sus empresas públicas es garantizar que los planes de remuneración para los miembros de los Directorios de la empresa pública promuevan el interés a largo plazo de la empresa y permitan atraer y motivar a profesionales calificados. Una remuneración apropiada para los directores, es un elemento clave para desarrollar una cultura de profesionalismo entre éstos.

Sin embargo, el sistema de retribución establecido en el artículo 33 LOSBN, señala que los miembros de junta de la banca estatal tienen derecho al cobro de honorarios por la asistencia puntual a las sesiones, honorarios en forma de dietas fijas, que serán las únicas remuneraciones que podrán percibir por sus servicios, a lo que se suma que la Ley sobre Pago de Dietas a Directivos de Instituciones Autónomas establece un máximo de 8 sesiones que se pueden remunerar al mes.

Ahora, si bien las buenas prácticas de gobierno recomiendan la publicación de los registros de asistencia para facilitar la legitimidad de la remuneración, establecen también que se deben tomar en cuenta que los que tienen compromisos intensivos, como representación de la entidad en eventos, o participación en los comités de auditoria o de riesgo, pueden requerir una compensación adicional significativa.

No obstante, la Procuraduría General de la República ha señalado en su Dictamen C-390-2006 del 4 de octubre del 2006 que las dietas no son la forma de retribuir el ejercicio de otras actividades relacionadas con su cargo, y la Ley contra la Corrupción y el Enriquecimiento Ilícito expresamente prohíbe en su artículo 16 a los servidores públicos percibir 
compensaciones salariales distintas de las retribuciones contempladas en el Régimen de Derecho público propio de su relación de servicio.

Así pues, lo establecido en cuanto al monto y máximo de las dietas a pagar, y el hecho de que no están sujetas a resultados obtenidos, puede desincentivar a profesionales de alto nivel a ser miembros de órganos directivos en la banca estatal, por lo que se propone se realice un estudio comparativo entre las políticas de retribución de los miembros de juntas directivas en el sector bancario, y que se admitan paquetes de remuneraciones para los directores, donde se combinen pagos fijos con convenios de incentivos, para lo cual se tendría que derogar parcialmente el artículo 33 citado.

\section{Independencia}

Los miembros deben expresar sus opiniones con independencia de los accionistas u otros órganos con poder de control, intereses políticos o intereses indebidos, siendo que específicamente los Directorios de las empresas públicas deben estar protegidos de una interferencia política indebida y directa que podría distraer su atención del logro de los objetivos acordados con el Estado y con la entidad propietaria.

La LOSBN, y las Directrices de la CGR establecen la obligación de actuar conforme a su criterio en la dirección y administración del Banco, de forma tal que exista independencia de grupos internos y externos, así como mantener la neutralidad política.
No obstante los miembros de Juntas Directivas de los bancos estatales son elegidos por el Consejo de Gobierno del partido político electo, son generalmente partidistas, así que no se puede hablar de una real ni percibida neutralidad política en estos órganos. Por esto se propone, un cambio en el proceso de elección y nombramiento de los directivos.

Política de rotación

Es importante que exista una rotación de miembros estructurada de manera tal que asegure una cierta continuidad de los conocimientos. Sin embargo, la LOSBN lo que establece en su artículo 24 es un plazo de nombramiento de ocho años, con posibilidad de reelección.

La Ley 4646 originó lo que hoy conocemos como el sistema $4 / 3$, cuatro del gobierno que entra y tres del gobierno anterior, que responde a una estructura bipartidista, en un modelo de toma decisiones colegiadas de garantizada mayoría para un periodo de cuatro años.

Dado que dicha reelección y rotación de los miembros está sujeta principalmente al partido político que resulte electo cada cuatro años, se considera que lo ideal sería que los plazos de los nombramientos sean más amplios que el período presidencial, por lo que sería recomendable un plazo de 6 años con posibilidad de reelección. Lo anterior implica una reforma al artículo 24 de la LOSBN y se recomienda eliminar la rotación $4 / 3$.

Control de la eficacia de las prácticas de gobierno de la sociedad, y la introducción de los cambios necesarios. 
La evaluación de las prácticas de gobierno corporativo de una empresa inicia desde su cúpula, y en virtud de que los miembros de junta directiva deben responder por el funcionamiento y solidez del banco, es importante que desarrollen y mantengan un nivel adecuado de conocimiento y experiencia a medida que el banco crece en tamaño y complejidad, al mismo tiempo que conozcan colectivamente cada tipo de actividad financiera importante que el banco pretenda realizar.

Para promover juntas competentes, es una buena práctica que los miembros del Consejo puedan tener acceso a programas de capacitación complementada con evaluaciones periódicas, las cuales pueden ser una herramienta eficaz para mejorar el funcionamiento de la junta, y para medir el desempeño de sus miembros de una manera constructiva y reflexiva.

La reelección ofrece una ocasión conveniente para realizar la evaluación de idoneidad, toda vez que las juntas necesitan periódicamente actualizar sus miembros y hacer los cambios necesarios.

En Costa Rica, sin embargo, el Reglamento de Gobierno Corporativo establece lo descrito, empero, queda supeditado a lo que establece la Ley al respecto, la cual limita la posibilidad de cambio en las prácticas que presenten debilidades, en tanto la LOSBN es omisa en cuanto a aspectos sobre capacitación y evaluación de las juntas directivas.
El artículo 24 de la LOSBN establece que los miembros pueden ser reelectos, pero no se refiere a los criterios para reelección, no estando sometidos a resultados de una evaluación de su gestión.

Una vez realizado el nombramiento de los directores y que éstos hayan entrado en funciones, el Consejo de Gobierno no podrá revocarlos, de acuerdo con el artículo 25 de esta ley que establece que los miembros de la junta serán inamovibles durante el período para que fueran designados, excepto en una serie de causales dentro de las cuales no se prevé la posibilidad de retirar a miembros cuya participación no sea óptima para el funcionamiento eficaz de la junta, es decir, que no estén haciendo aportes reales, que no sean participativos, activos, informados, o que sólo asistan a sesión por ganarse una dieta.

Es por ello que se recomienda que se desarrolle mediante reglamento que los bancos deben tener procedimientos adecuados de inducción de los directores nuevos, en los cuales se incluyan al menos el negocio, operaciones, productos $\mathrm{y}$ servicios de la empresa, estrategia, explicación de los estados financieros, principales riesgos, y sus responsabilidades legales. Asimismo, los miembros deben tener acceso a programas de capacitación que les actualice su conocimiento.

Además, en virtud de que la Ley no establece nada al respecto, sería importante se desarrollara mediante 


\section{Alejandra Gutiérrez Segnini}

norma reglamentaria también el requerimiento de realizar evaluaciones periódicas, lo cual debe ser clave para efectos de reelección. Igualmente debería habilitarse la excepción a la inamovilidad de los miembros cuya participación no sea óptima (de conformidad con los resultados de dichas evaluaciones), lo cual significa que se debería reformar el artículo 25 de la LOSBN para efectos de agregar ésta causal.

\section{Conclusiones}

La idea de una junta directiva no es que exista por mera obligación legal o que sea "decorativa", ni que todo "se cocine" antes de llegar a dicho órgano para su mera aprobación, como lamentablemente ocurre en la práctica. Lo ideal es que sea un órgano activo dentro de gobierno corporativo con un sistema de contrapesos que garantice la debida organización y supervisión de la entidad.

Tampoco es conveniente que sus miembros por desconocimiento de los temas lleguen a obstaculizar la buena labor de la gerencia, ni que se recargue cada ocho años en la Administración la enseñanza del negocio a directivos entrantes totalmente ajenos al sector.

A este órgano colegiado la Ley le ha encomendado dirigir la política financiera y económica del Banco, lo cual conlleva establecer las políticas que regirán su proceso de Administración Integral de Riesgos, incluyendo la vigilancia de la administración superior de la entidad. Por ello se le llama el "corazón del gobierno corporativo". No podemos permitir que la junta directiva sea en sí misma, un factor de riesgo para la entidad financiera.

$\mathrm{Si}$ bien es cierto un buen gobierno corporativo necesita bases jurídicas, reguladoras e institucionales que sean adecuadas y eficaces, con este artículo y las recomendaciones que se presentan, se busca sobre todo hacer consciencia de las implicaciones del tema, donde es mejor prevenir que sancionar, por lo que es vital modificar la visión que se maneja en Costa Rica de las juntas directivas de las empresas públicas, especialmente las de los bancos, que desarrollan actividades tan complejas. Las personas que integran las juntas directivas que lideran y fijan el norte de estas entidades financieras - que aportan más del 50\% de los activos del sistema financiero nacional-, deben tener el perfil necesario para llevar a cabo sus tareas eficazmente, y así dejar de lado de una vez por todas los nombramientos basados en factores de política partidista, amistad o parentesco cual "mera vitrina de nombres distinguidos sin información ni real influencia en el funcionamiento de la institución", poniendo en riesgo la estabilidad del sistema financiero y económico del país. 


\section{Referencias}

Arias, Benavides y Monge (1992). Eficacia de una Junta Directiva. San José, Costa Rica, UCR.

Charkham, Jonathan (2003). Guidance for the Directors of Banks. Global Corporate Governance Forum Focus 2. The International Bank for Reconstruction and Development / The World Bank. 2003 www.igccostarica.org/?action=biblioteca

Comité de Supervisión Bancaria de Basilea, Banco de pagos internacionales (Febrero, 2006). La mejora del gobierno corporativo en organizaciones bancarias. www.bis.org/publ/bcbs122es.pdf

Consultoría IAAG\&Corporate Finance. Cámara de Bancos e Instituciones Financieras de Costa Rica, Academia Bancaria Centroamericana (30 de agosto a 3 de setiembre 2010). Seminario Interrelación entre gobierno corporativo y la administración de riesgos: Retos y oportunidades.

Dictamen C-024-2004 del 20 de enero de 2004 de la Procuraduría General de la República http://www.pgr.go.cr/scij/index pgr.asp

Directrices Generales sobre Principios y Enunciados Éticos a Observar por Parte de los Jerarcas, Titulares Subordinados, Funcionarios de La Contraloría General de la República, Auditorias Internas y Servidores Públicos en General No D-2-2004-CO http://www.pgr.go.cr/scij/index_pgr.asp

Directorate for Financial and Enterprise Affairs, OECD Steering Group on Corporate Governance (Febrero, 2010). CORPORATE GOVERNANCE AND THE FINANCIAL CRISIS. Conclusions and emerging good practices to enhance implementation of the Principles. www.oecd.org/dataoecd/53/62/44679170.pdf

Federación Latinoamericana de Bancos (Octubre 2007) Prácticas de Buen Gobierno Corporativo en el Sector Financiero Latinoamericano. www.felaban.com/archivos publicaciones/buen gobierno.pdf

Federación latinoamericana de bancos -Felaban- (Octubre 2008) Código marco de prácticas de buen gobierno corporativo para entidades del sector financiero latinoamericano. www.felaban.com/archivos publicaciones/codigo marco.pdf

Funes Orellana, Oscar (2006). Responsabilidad civil de gerentes y miembros de Junta Directiva de los Bancos en Costa Rica en sus decisiones y actuaciones. San José, Costa Rica, UCR.

Gutiérrez Segnini, María Alejandra (2011). Riesgo de Gobierno Corporativo Derivado de las Juntas Directivas de la Banca Estatal Costarricense. San José, Costa Rica, UNED.

Informe No. DFOE-PG-IF-07-2011. Informe sobre los Perfiles Gerenciales en algunos Ministerios $e$ Instituciones del Sector Público. Contraloría General de la República, 18 de octubre 2011

Instituto Brasileiro de Governança Corporativa. Code of Best Practice of Corporate Governance. http://www.ibgc.org.br/CodeBestPractices.aspx

Instituto de gobierno corporativo Panamá (2010). Guía de Buenas Prácticas de Gobierno Corporativo. http://www.igc-panama.org/index.php?option=com_content\&view=article\&id=15\%3Aguia-de-buenaspracticas-\&catid $=2 \% 3$ Alatest-news \&Itemid $=1$

Kirkpatrick, Grant y OECD Steering Group on Corporate Governance (2009). The Corporate Governance Lessons from the Financial Crisis. www.oecd.org/dataoecd/32/1/42229620.pdf

Ladipo y Nestor (2009). Bank Boards and the Financial Crisis. A corporate governance study of the 25 largest European Banks. Nestor Advisors Ltd. www.nestoradvisors.co.uk/news/news/news-article

Ley Orgánica del Sistema Bancario Nacional. Ley $\mathrm{N}^{\circ} 1644$. http://www.pgr.go.cr/scij/index_pgr.asp

Ley contra la Corrupción y el Enriquecimiento Ilícito en la Función Pública. Ley № 8422 http://www.pgr.go.cr/scij/index_pgr.asp

Ley General de Control Interno. No 8292 http://www.pgr.go.cr/scij/index_pgr.asp

Ley Número: 4646. Modifica Integración de Juntas Directivas de Instituciones Autónomas http://www.pgr.go.cr/scij/index_pgr.asp

Ley Orgánica del Banco Central de Costa Rica, No. 7558 http://www.pgr.go.cr/scij/index pgr.asp

Ley General de Administración Pública No. 6227 http://www.pgr.go.cr/scij/index pgr.asp

Ley sobre Pago de Dietas a Directivos de Instituciones Autónomas, http://www.pgr.go.cr/scij/index pgr.asp

Nestor Advisors Ltd. Nota de investigación 0109 (Abril, 2009). Gobernance in crisis: A comparative case study of six US investment banks. Reino Unido. http://www.igc-costarica.org/?action=biblioteca

OECD (Junio, 2009). Corporate Governance and the Financial Crisis: Key Findings and Main Messages. www.oecd.org/dataoecd/3/10/43056196.pdf

OECD (2011). Directrices de la OCDE sobre el gobierno corporativo de las empresas públicas. Traducido de la versión original en inglés publicada con el título: OECD Guidelines on Corporate Governance of Stateowned Enterprises. $\quad$ www.oecd.org/daf/corporateaffairs/corporategovernanceofstateownedenterprises/48632643.pdf 
OECD (2004). Principios de gobierno corporativo de la OECD. Traducido de la versión original en inglés publicada con el título: OECD Principles of Corporate Governance. www.oecd.org/dataoecd/47/25/37191543.pdf

OECD (2008). Using the OECD Principles of Corporate Governance. A BOARDROOM PERSPECTIVE. www.oecd.org/dataoecd/20/60/40823806.pdf

OCDE (2004). "White paper" sobre gobierno corporativo en América Latina. www.oecd.org/dataoecd/5/13/22368983.pdf

Osborne, Simon (2008). Board performance evaluation. Institute of Chartered Secretaries and Administrators (ICSA). Board Performance Unit. www.icsa.org.uk/products-services/icsa-board-evaluation

Procuraduría General de la República (4 de octubre del 2006). Dictamen C-390-200. http://www.pgr.go.cr/scij/index pgr.asp

Programa Kemmerer -- desarrollo e integración de los mercados financieros -- de la Corporación Andina de Fomento. Gobierno Corporativo: lo que todo empresario debe saber. www.igccostarica.org/?action=biblioteca

Reglamento de Gobierno Corporativo emitido por el CONASSIF. http://www.pgr.go.cr/scij/index pgr.asp

Reglamento para la Autorización y Ejecución de Operaciones con Derivados Cambiarios Acuerdo SUGEF 9-08, http://www.pgr.go.cr/scij/index pgr.asp

Reglamento Sobre Administración Integral De Riesgos. Acuerdo SUGEF 2-10, http://www.pgr.go.cr/scij/index pgr.asp

Reglamento para Juzgar la Situación Económica-financiera de las Entidades Fiscalizadas Acuerdo SUGEF 24oo http://www.pgr.go.cr/scij/index pgr.asp

Reglamento sobre el Grupo Vinculado a la Entidad acuerdo SUGEF 4-04 http://www.pgr.go.cr/scij/index pgr.asp

Resolución 001000-F-S1-2010, expediente 08-000522-1027-CA de la SALA PRIMERA DE LA CORTE SUPREMA DE JUSTICIA. San José, a las nueve horas treinta y cinco minutos del veintiséis de agosto de dos mil diez: http://www.pgr.go.cr/scij/index pgr.asp

XII Congreso Latinoamericano de desarrollo de la Gestión Humana y la Responsabilidad Social. Federación Latinoamericana de Bancos y Asociación de Bancos de Perú (2009) .Las debilidades del gobierno Corporativo en las entidades financieras y el aspecto ético de su gestión. www.felaban.com/archivos/memoria anualog/clade/luis humberto.pdf

REFORM REALISM AND THE BOARDROOM, By Philip TN Koh FCIS, Mah-Kamariyah \& Philip Koh Advocates \& Solicitors, and a Member of the Forum's Private Sector Advisory Group. The Chartered Secretary Malaysia, September www.ifc.org/ifcext/cgf.nsf/.../Final+version++GCGF+PSO+issue+6.p

\title{
Nota acerca de la autora
}

\section{María Alejandra Gutiérrez Segnini}

Licenciada en Derecho de la Universidad de Costa Rica y Master en Derecho Económico con énfasis en Comercio Internacional de la Universidad Estatal a Distancia (UNED)

\author{
Abogada de temas regulatorios en la División Jurídica de banco estatal \\ costarricense.
}

Correoelectrónico: mariale.gutierrez@gmail.com 